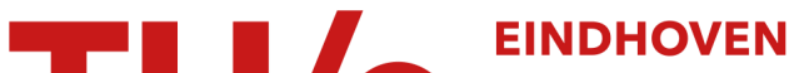 UNIVERSITY OF TECHNOLOGY
}

\section{Gbit/s Transmission in a 2D Beam Steering AWG-Based Optical Wireless Communication System}

Citation for published version (APA):

Gomez-Agis, F., van der Heide, S. P., Okonkwo, C. M., Tangdiongga, E., \& Koonen, A. M. J. (2017). 112 Gbit/s Transmission in a 2D Beam Steering AWG-Based Optical Wireless Communication System. In 43rd European Conference on Optical Communication, ECOC 2017 (Vol. 2017-September, pp. 1-3). Institute of Electrical and Electronics Engineers. https://doi.org/10.1109/ECOC.2017.8346059

DOI:

10.1109/ECOC.2017.8346059

Document status and date:

Published: 21/09/2017

\section{Document Version:}

Accepted manuscript including changes made at the peer-review stage

\section{Please check the document version of this publication:}

- A submitted manuscript is the version of the article upon submission and before peer-review. There can be important differences between the submitted version and the official published version of record. People interested in the research are advised to contact the author for the final version of the publication, or visit the $\mathrm{DOI}$ to the publisher's website.

- The final author version and the galley proof are versions of the publication after peer review.

- The final published version features the final layout of the paper including the volume, issue and page numbers.

Link to publication

\section{General rights}

Copyright and moral rights for the publications made accessible in the public portal are retained by the authors and/or other copyright owners and it is a condition of accessing publications that users recognise and abide by the legal requirements associated with these rights.

- Users may download and print one copy of any publication from the public portal for the purpose of private study or research.

- You may not further distribute the material or use it for any profit-making activity or commercial gain

- You may freely distribute the URL identifying the publication in the public portal.

If the publication is distributed under the terms of Article $25 \mathrm{fa}$ of the Dutch Copyright Act, indicated by the "Taverne" license above, please follow below link for the End User Agreement:

www.tue.nl/taverne

Take down policy

If you believe that this document breaches copyright please contact us at:

openaccess@tue.nl

providing details and we will investigate your claim. 


\title{
112 Gbit/s Transmission in a 2D Beam Steering AWG-Based Optical Wireless Communication System
}

\author{
F. Gomez-Agis, S. P. van de Heide, C.M. Okonkwo, E. Tangdiongga, and A.M.J. Koonen \\ Institute for Photonic Integration (IPI), Eindhoven University of Technology, PO Box 513, \\ 5600MB Eindhoven, The Netherlands. \\ f.gomez.agis@tue.nl
}

\begin{abstract}
Gbit/s transmission in a 2D infrared AWG-based beam steering system is demonstrated by employing PAM-4 modulation, pulse-shaping, pre-compensation and equalisation techniques in a SOA-based pre-amplified direct-detection scheme. BER performances below HD-FEC (3.8E-3) have been achieved.
\end{abstract}

\section{Introduction}

Infrared (IR) beam communications is an evolving and an alternative technology that enables high capacity data-transport, providing power efficiency, a wealth of unregulated bandwidth, immunity to radio interference, and inherent security in indoor networks. Besides these benefits, the availability of low-cost IR components used for conventional optical fibre communication systems, facilitates its implementation since a high power budget is possible due to the more relaxed eye safety regulations and higher photoreceiver sensitivity achievable with respect to visible light. Several 2D beam steering approaches capable of handling high capacity data-transport have been proposed. For instance, a 2D-steered directdetection system using diffractive optics has been demonstrated to handle data transmission up to $42.8 \mathrm{Gbit} / \mathrm{s}$ per beam ${ }^{1}$ whilst systems using array-waveguide gratings (AWG) have been demonstrated at up to $35 \mathrm{Gbit} / \mathrm{s}$ per beam $^{2}$. Data capacity has been increased further, enabling $50 \mathrm{Gbit} / \mathrm{s}$ in spatial-light modulator (SLM)-based systems but this requires the more complex/costly coherentdetection schemes ${ }^{3}$.

In this paper, it is demonstrated that in a $2 \mathrm{D}$ AWG-based beam steering system it is possible to handle up to $112 \mathrm{Gbit} / \mathrm{s}$ using appropriate digital signal processing (DSP) and an optical receiver configuration that operates, around bandwidth limitations imposed by the AWG and RF connections and devices, and also with limited optical power in the receiver, due to optical aberrations (multiple focal points) introduced in the expanded beam. This is achieved using a PAM-4 modulation format, pulse shaping, pre-compensation and equalisation techniques for the bandwidth restrictions, and a pre-amplification scheme, based on a semiconductor optical amplifier

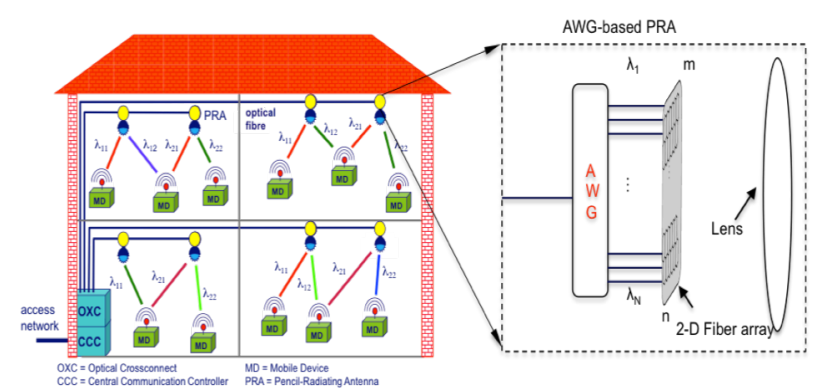

Fig. 1: Schematic representation of an indoor OWC system with AWG-based PRA.

(SOA) which can be photonic-integrated with a receiver to increase the sensitivity.

\section{Indoor OWC system with AWG-based PRAs}

As represented in Fig.1, an indoor optical wireless communication (OWC) system that uses AWG-based PRAs consists of a central communication controller (CCC) that dynamically routes the data streams to and from multiple pencil-radiating antennas (PRAs) located in different rooms and connects with the fibre-based access network via a transparent optical cross-connect (OXC) switch ${ }^{4}$. The PRAs are fully passive and their signals are fed by the CCC. In particular, AWG-based PRAs are capable of 2D dimensional beam scanning by changing the operating wavelength. The $N$ outputs of the AWG that each carry a separate particular wavelength are connected to the input ports of a 2D $m \times n$ fibre array and a lens placed in front of it, and provide an array of spots in the image plane of the lens on the user location. Note that when the laser is tuned across the full wavelength range of the AWG channels, each time a wavelength falls in an AWG passband, the beam is steered to the corresponding spot in the image plane of the lens. This implies, the larger the number of ports in the AWG, the larger the covering area can be. Design criteria of the fibre array and parameters of the lens can 
be determined using geometrical optics ${ }^{5}$. The return path for each user is established by 60 $\mathrm{GHz}$ radio-over-fibre techniques (not shown in Fig. 1 and not discussed in this paper) and also serves for user localization and tracking ${ }^{6}$.

\section{Enabling high-data capacity transmission in AWG-based OWC systems; principle of operation}

High-data capacity transmission in AWG-based OWC systems is based on the diagram shown in Fig. 2. A digital-to-analog (DAC) converter provides the data signal in the electrical domain that modulates the optical wavelength provided by the CCC into the AWG-based PRA, which expands and directs the beam to where the optical receiver, representing the user, is placed at a distance $d$ from the transmitter. Since the PRA is composed of a bandwidth-limited AWG and dispersive optics, some constraints to increase data capacity are imposed. Moreover, electrical connections from the DAC, RF amplifiers, electrical cables and the frequency response of the intensity-modulator, also introduce bandwidth limitations on the data rate that can be conveyed onto the optical signal. In order to mitigate for these effects, DSP is extremely useful. It can compensate for attenuation at high frequencies and for distortions in the frequency response of RF components. It can adapt the data waveform to better fit in the available bandwidth in the transmitter and it is possible to generate highorder modulation formats so more bits $/ \mathrm{s} / \mathrm{Hz}$ can be sent. As for the receiver side, the received optical power is somewhat reduced due to multiple focal points caused by optical aberrations in the expanded beam resulting from the imaging optics, when trying to couple light into the receiver. Although larger core fibres $(500 \mu \mathrm{m})$ could be used, extra losses arise due to tapering into the receiver. An optical component enabling not only the reception of high data capacity transmission because it provides optical gain, but also because of its capability for photonic integration with a PIN-TIA device and low power consumption is the linear $\mathrm{SOA}^{7}$.

\section{Experimental validation of high-data capacity transmission}

The AWG-based PRA has a bandwidth of $0.31 \mathrm{~nm}(38.68 \mathrm{GHz})$ with channel wavelengths ranging from $1529.10 \mathrm{~nm}$ to $1569.80 \mathrm{~nm}$. The $N$ outputs of the AWG are connected to a $9 \times 92 \mathrm{D}$ fibre array with $1.3 \mathrm{~mm}$ pitch. 42- and 56-Gbaud PAM-4 signals were digitally generated with raised cosine waveforms and rolloff of 0.2 using 19 taps. A 9-tap pre-compensation filter was used to mitigate the effects of limited bandwidth caused by transmitter components such as the AWG bandwidth, intensity modulator response and electrical connections in-between. The waveform was uploaded to a Keysight M8196A arbitrary-waveform generator operating at 84 GS/s and amplified before being applied to a single-drive $40 \mathrm{GHz}$ bandwidth Mach-Zehnder intensity-modulator. The modulated optical beam from the central output port of the fibre array (port no. 44), corresponding to $1545.519 \mathrm{~nm}$, was amplified by an EDFA prior to being launched into free-space and propagated into a condenser lens of $40 \mathrm{~cm}$ focal length and $20 \mathrm{~cm}$ diameter. The measured optical power into free-space was limited to $+10 \mathrm{dBm}$; respecting the eye-safety limits. The optical receiver was placed at the centre of the expanded beam (around $8.5 \mathrm{~cm}$ diameter) at a distance of $3.4 \mathrm{~m}$. The received optical power was coupled into a $10 \mu \mathrm{m}$ core optical fibre via a telescopic lens with $6 \mathrm{~cm}$ aperture for beam narrowing, followed by a $3 \mathrm{~mm}$ aperture lens and a high-precision coupling stage. Due to optical aberrations introduced in the expanded beam, the maximum optical power that was possible at the optical receiver, due to multiple focal points, was $-9.5 \mathrm{dBm}$; not enough for performance evaluation for the targeted $112 \mathrm{Gbit} / \mathrm{s}$ signal. In order to enable the receiver to operate at such a high bit-rate, we implemented a pre-amplified direct-detection scheme, which can be photonic integrated, using a linear semiconductor

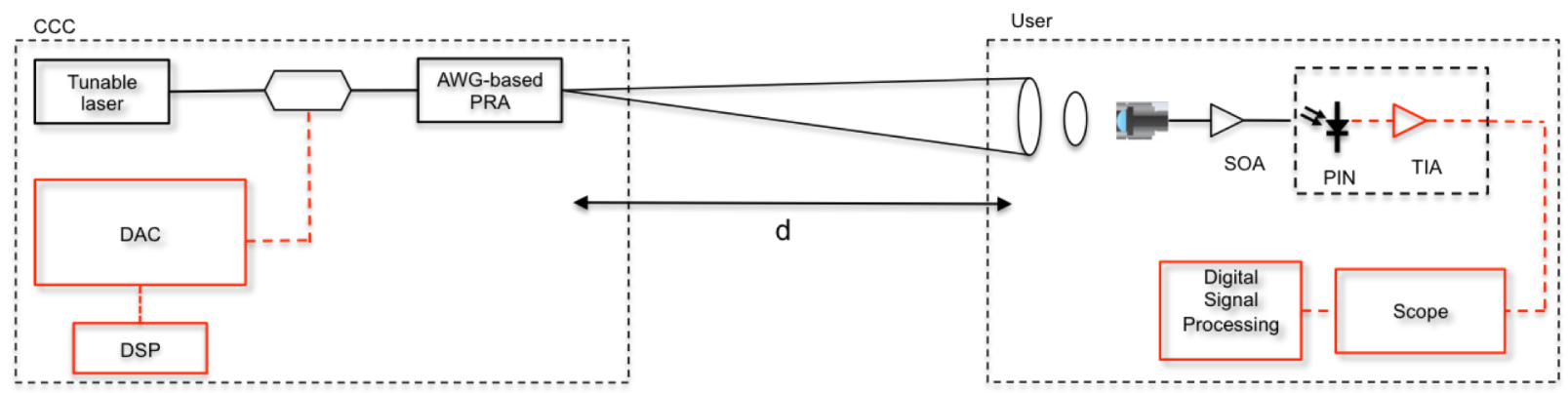

Fig. 2: Enabling high-data capacity transmission in an AWG-based OWC system by relying on DSP and on a pre-amplified scheme based on a SOA in the optical receiver. Digital-to-Analog converter, Central communication controller (CCC). 


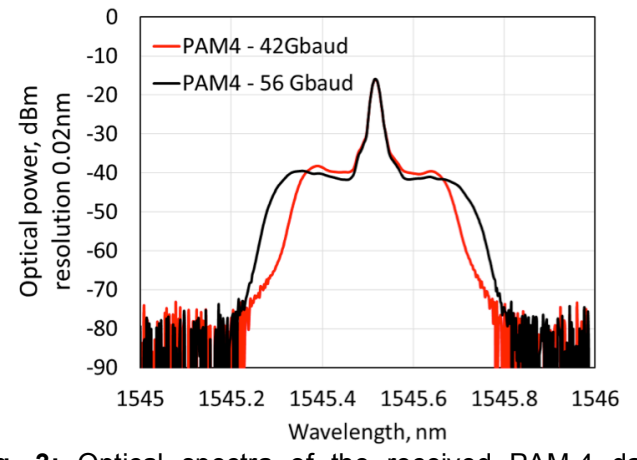

Fig. 3: Optical spectra of the received PAM-4 data signals before SOA amplification.

amplifier (SOA) followed by a $70 \mathrm{GHz}$ PIN and a $35 \mathrm{GHz}$ RF amplifier. The linear SOA drive current was set to $90 \mathrm{~mA}$, providing $10 \mathrm{~dB}$ gain to the received signal. The detected data signals were digitized by a $80 \mathrm{GS} / \mathrm{s}$ Keysight MSOV334A oscilloscope and DSP was performed offline on the 2.2 million bits captures. For instance, resampling, clockrecovery, 21-tap feed-forward equalization and error counting were applied. Fig. 3 shows the optical spectra corresponding to both signals at the receiver side before being amplified by the linear SOA. Bit-error-rate performances for two different capacity PAM-4 signals transmitted via the AWG-based PRA are shown in Fig.4: 56 Gbaud PAM-4 corresponding to $112 \mathrm{Gbit} / \mathrm{s}$ (100Gbit/s net after HD-FEC 12\% overhead) and 42 Gbaud PAM-4 corresponding to 84 Gbit/s. As for the 42 Gbaud PAM-4 signal, performances below HD-FEC were achieved with a received power of $-7.5 \mathrm{dBm}$. For this power, the BER was 1.73E-03. It can be observed that as the received optical power increases, error rates diminish. As for the 56 Gbaud PAM-4 signal, the performance below HD-FEC (3.8E-03) was achieved at $-4.5 \mathrm{dBm}$; namely $3 \mathrm{~dB}$ more power was required with respect to the 42 Gbaud PAM-4 signal. Nevertheless, an error floor is observed. The penalty and error floor arise mainly due to bandwidth limitations intrinsic to the AWG and to noise introduced by the SOA. The use of a linear SOA in the optical receiver is justified on one hand, because it can be photonic integrated along with a PIN-TIA device rendering the optical receiver compact. Approaches using InP membranes to improve IR light collection have been recently demonstrated ${ }^{8}$. On the other hand, the linear SOA provides enough gain with highly reduced patterning effects. This can be seen in the inset of Fig. 4 where the sampled eye diagrams for $0 \mathrm{dBm}$ optical power in the receiver is shown. The PAM-4 levels of the signals are clear and well recognized.

\section{Conclusions}

$112 \mathrm{Gbit} / \mathrm{s}$ and $84 \mathrm{Gbit} / \mathrm{s}$ data transmission were possible in a $0.31 \mathrm{~nm}$ bandwidth AWG-based

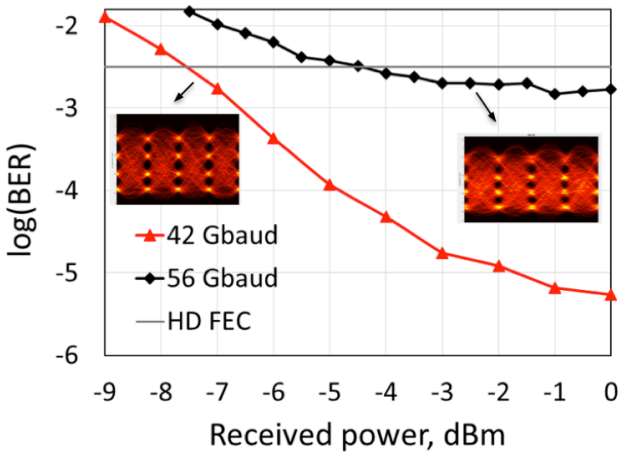

Fig. 4: BER performance of the received signals. The received signals have been amplified by the linear SOA.

OWC system by applying appropriate and minimal DSP complexity in the transmitted and received data signals, and by using a preamplified scheme based on a linear semiconductor optical amplifier (SOA) in the optical receiver. Photonic integration of SOA with PIN+TIA devices will provide a compact solution to enable high-data rates for OWC systems. With these improvements, BER performances below HD-FEC were achieved for both demonstrated data rates.

\section{Acknowledgements}

Funding from the ERC project BROWSE is gratefully acknowledged. Keysight Technologies is gratefully acknowledged for providing the instruments.

\section{References}

[1] C. W. Oh et al., "42.8 Gbit/s indoor optical wireless communication with 2-dimensional optical beamsteering," Proc. OFC, M2F3, Los Angeles (2015).

[2] A. M. Khalid et al., "Bi-directional 35-Gbit/s 2D Beam Steered Optical Wireless Downlink and 5-Gbit/s Localized $60-\mathrm{GHz}$ Communication Uplink for Hybrid Indoor Wireless Systems," Proc. OFC, Th1E6, Los Angeles (2017).

[3] A. Gomez et al., "A $50 \mathrm{~Gb} / \mathrm{s}$ Transparent Indoor Optical Wireless Communications Link With an Integrated Localization and Tracking System," Journal of Light. Technol., Vol. 34, no. 15, p. 2510 (2016).

[4] T. Koonen et al., "2D Beam-Steered High-Capacity Optical Wireless Communication," Proc. SUM, TuC2.2, Puerto Rico (2016).

[5] T. Koonen et al., "High-capacity Optical Wireless Communication using AWG Router for 2-Dimensional IR Beam Steering," Proc. OECC, Singapore (2017)

[6] K. Mekonnen, et al., "PIC-enabled dynamic bidirectional indoor network employing optical wireless and millimeter-wave radio techniques," Proc. ECOC, W1E3, Dusseldorf, (2016).

[7] D. Cotter, et al., "Nonlinear optics for high-speed digital information processing," Science, Vol. 286, p. 5444 (1999).

[8] Z. Cao, et al., "200 Gbps OOK Transmission over an Indoor Optical Wireless Link Enabled by an integrated Cascaded Aperture Optical Receiver," Proc. OFC, PDP Th5A.6, Los Angeles (2017). 